Martin J.L. Bucx MD PhD, Marinus H. van der Vegt MD,* Chris J. Snijders M Eng PhD, Theo Stijnen MSc PhD, $\ddagger$ Paul R. Wesselink DMD PhD§

\title{
Transverse forces exerted on the maxil- lary incisors during laryngoscopy
}

Purpose: In this study the effect of level of experience of the intubator on the forces applied by the Macintosh laryngoscope on the maxillary incisors in both the axial and transverse direction were investigated.

Methods: Five groups of different levels of experience (15 per group), staff anaesthetists, residents, nurse anaesthetists, surgeons and students, performed one laryngoscopy and subsequent intubation on an intubation manikin equipped with sensors to measure these forces.

Results: Maximal transverse forces oriented toward the base of the skull (Fmtpmax) were between 0 and $10 \mathrm{~N}$ in 46 cases $(61 \%)$, between 10 and $20 \mathrm{~N}$ in $21(28 \%)$ and $\geq 20 \mathrm{~N}$ (maximum $46.5 \mathrm{~N}$ ) in eight cases (11\%). The maximal values of the transverse forces oriented toward the intubator (Fmtnmax) were between 0 and $10 \mathrm{~N}$ in 69 cases (92\%), between 10, and $20 \mathrm{~N}$ in $3(4 \%)$ and $\geq 20 \mathrm{~N}$ (maximum $36.4 \mathrm{~N}$ ) in $3(4 \%$ ). Level of experience was related to Fmtpmax (Spearman: $P=$ $0.04, r=0.24)$. In addition, Fmtnmax was less in experienced intubators (anaesthetist and residents) than in inexperienced intubators (all other groups) (Student's $t$ test: $P=0.04$ ).

Conclusion: In contrast to the effect on forces exerted in the axial direction, experience proved to have a beneficial effect on the forces in the transverse direction.

\section{Key words}

ANAESTHETIC TECHNIQUES: laryngoscopy;

EQUIPMENT: laryngoscopes;

INTUBATION, TRACHEAL: technique;

LARYNX: laryngoscopy.

From the Department of Anaesthesia, Academic Medical Center, University of Amsterdam, the Departments of *Anaesthesia, †Biomedical Physics and Technology, and $\ddagger$ Epidemiology and Biostatistics, Erasmus University Rotterdam, and the §Academic Center for Dentistry, Amsterdam, The Netherlands.

Address correspondence to: Dr. Martin J.L. Bucx, Academic Medical Center, University of Amsterdam, Department of Anaesthesia, PO Box 22700, 1100 De Amsterdam, The Netherlands.

Accepted for publication 2nd March, 1996.
Objectif: Vérifier l'influence de l'expérience de l'intubateur sur les forces appliquées par le laryngoscope Macintosh sur les incisives maxillaires tant dans la direction transversale qu'axiale.

Méthodes: Cinq groupes possédant des degrés variés d'expérience (15 par groupe) anesthésistes, résidents, infirmières anesthésistes, chirurgiens et étudiants ont effectué une laryngoscopie suivie de l'intubation sur un mannequin d'intubation équipé de senseurs capables de mesurer ces forces.

Résultats: Les forces transversales maximales orientées vers la base du crâne (Fmtpmax) se situaient entre 0 et $10 \mathrm{~N}$ dans 46 cas $(61 \%)$, entre 10 et $20 \mathrm{~N}$ dans 21 (28\%) et $\geq 20 \mathrm{~N}$ (maximum $46,5 \mathrm{~N}$ ) dans huit cas (11\%). Les valeurs maximales des forces orientées vers l'intubateur (Fmtnmax) se situaient entre 0 et $10 \mathrm{~N}$ dans 69 cas (92\%), entre 10 et $20 \mathrm{~N}$ dans $3(4 \%)$ et $\geq 20 \mathrm{~N}$ (maximum $26,4 \mathrm{~N}$ ) dans $3(4 \%$ ). Le degré d'expérience était en rapport avec Fmtpmax (Spearman: $P=0,04, r=$ 0,24). De plus, Fmtnmax était plus bas chez les intubateurs expérimentés (anesthésistes et résidents) que chez les intubateurs inexpérimentés (tous les autres groupes) (test $t$ de Student: $P=0,04$ )

Conclusion: Contrairement aux forces exercées en direction axiale, l'expérience a une influence bénéfique sur les forces exercées en direction transversale.

The application of force on the maxillary incisors during routine laryngoscopy is considered to be in contradiction to accepted professional standards. ${ }^{1,2}$ However, in a recent study using a laryngoscope equipped with force sensors, it was demonstrated that in the majority of patients, anaesthetists exert great forces on the incisor teeth. ${ }^{3}$ This observation was confirmed using an intubation manikin, ${ }^{4}$ but a relationship between level of experience and the amount of force applied could not be established. However, the accuracy of the instrument used in both studies was limited and only forces parallel to the axis of the incisor teeth could be measured. ${ }^{3.4}$ In contrast to large axial forces, which incisor teeth are able to withstand during normal physiological function, relatively small transverse forces may cause damage to teeth during laryngoscopy. ${ }^{5}$ 


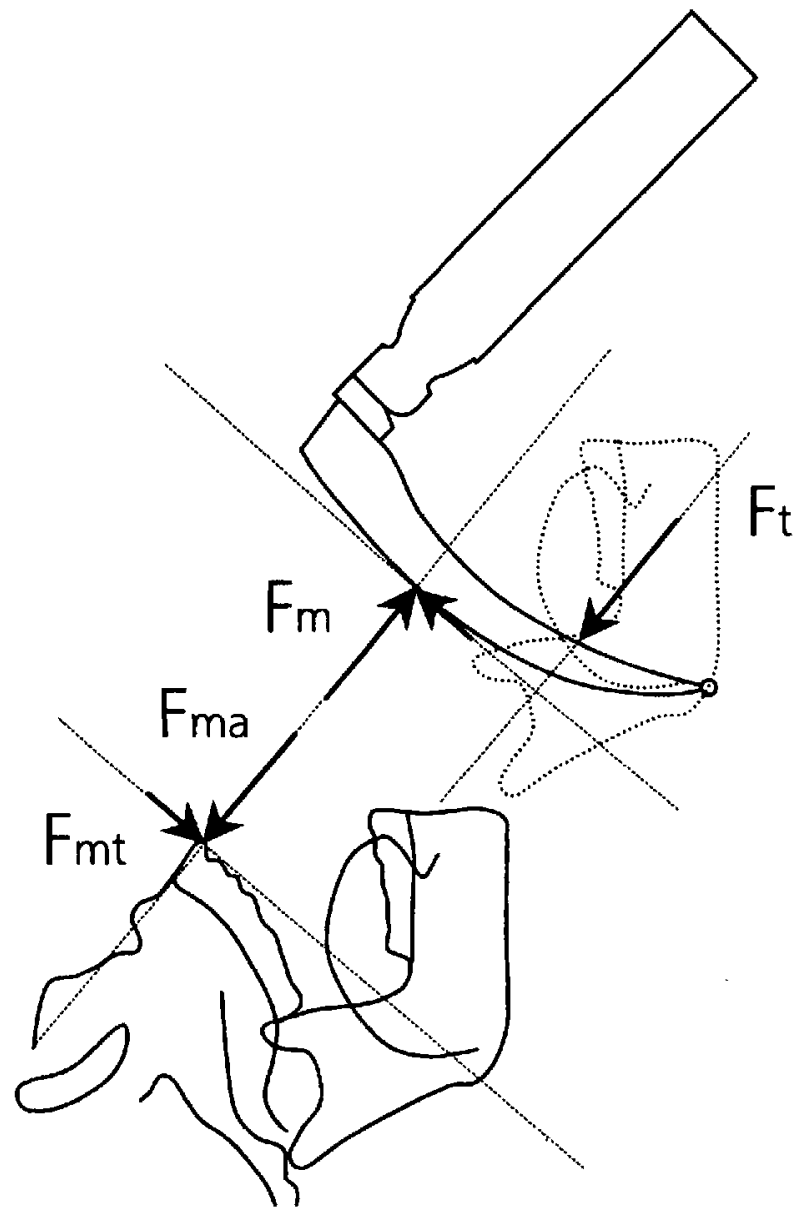

FIGURE 1 Schematic representation of the forces applied during laryngoscopy. Only forces acting on blade and teeth are drawn. $\mathrm{Ft}$ and $\mathrm{Fm}$, forces exerted on the tongue and on the maxillary incisors in the axial direction, respectively. Fma and Fmt, forces exerted on the incisors in the axial and transverse direction, respectively. Fm equals Fma, action is reaction.

This study was conducted to investigate the amount of transverse force applied to the maxillary incisors during laryngoscopy using the Macintosh laryngoscope. Axial forces were measured with greater accuracy than previously. Also the effect of level of experience on these forces and the duration of laryngoscopy, the best view obtained and the success of intubation was studied.

\section{Methods}

A pilot study was conducted to test whether the unmodified Laerdal Airway Management Trainer was a suitable manikin. Ten anaesthetists and 10 senior residents performed a total of 20 laryngoscopies and subsequent

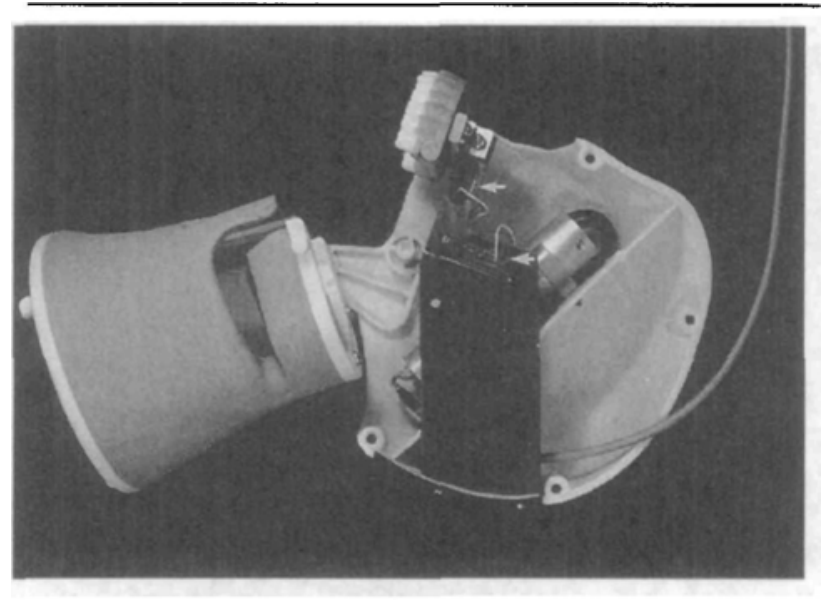

FIGURE 2 Photograph showing the interior of the modified manikin. The arrows indicate the position of the two sensors.

intubations using a modification ${ }^{3}$ to a previously described curved blade laryngoscope. ${ }^{6}$ Between the handle and the blade of this laryngoscope a combined moment and shear force sensor, based on the strain gauge technique, was positioned. This configuration of sensors allowed estimation of the forces applied to the tongue $(\mathrm{Ft})$ and to the maxillary incisors $(\mathrm{Fm})$, provided that the application points of these forces on the blade were known. ${ }^{3}$

The results of the pilot study indicated that very high forces were needed to perform laryngoscopy in this manikin (Table I). As these forces were not considered to be representative of the forces used during routine laryngoscopy in patients, it was decided to modify the manikin to reduce the forces required. This was accomplished by displacing the larynx into a more posterior position, a modification which was not visible from the outside. In addition, two shear-force sensors were built into the maxilla of the manikin, enabling measurement of the forces applied to the maxillary incisors in the axial (Fma) and the transverse (Fmt) direction (Figures 1 and 2). The sensors were of the same type as described earlier ${ }^{6.7}$ having an excellent linearity (deviation $<1 \%$ ) and reproducibility (deviation $\ll 1 \%$ ).

When the transverse forces were exerted towards the base of the skull they were defined as being exerted in the positive direction (Fmtp), whereas forces toward the intubator were defined as negative (Fmtn).

The application points in the modified intubation manikin were determined by six investigators each performing seven laryngoscopies without touching the maxillary incisors. ${ }^{3}$ Seventy-five participants were divided into five groups (15 per group) of different levels of experience. Group 1 were staff anaesthetists; 


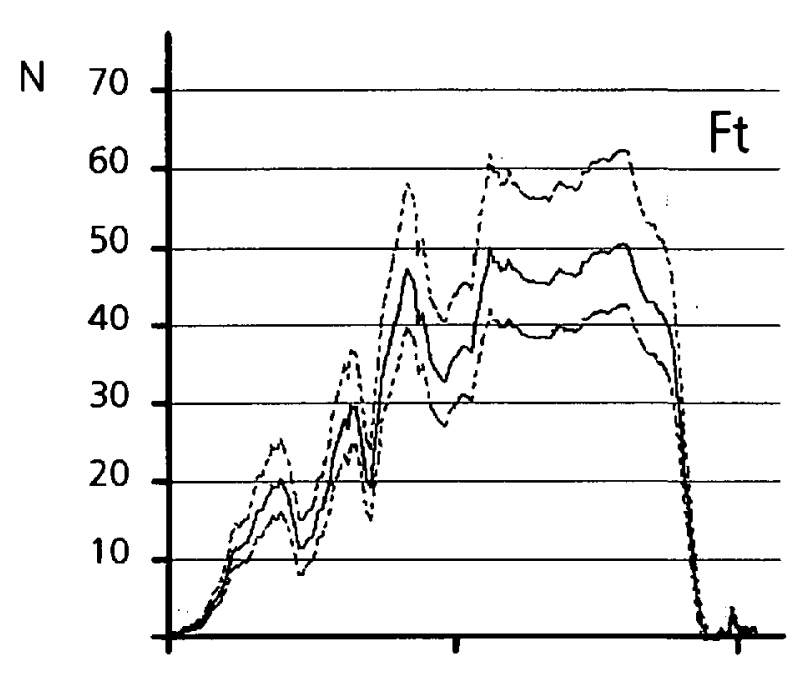

Group 2 were residents in anaesthesia (>two years experience or $>300$ tracheal intubations); Group 3 nurse anaesthetists; Group 4 consultants or senior residents in surgical fields with previous successful intubation experience in patients (referred to hereafter as surgeons), and Group 5 were medical students. The trachea in the modified manikin was intubated by each participant using the measuring laryngoscope. A maximum of $60 \mathrm{sec}$ was allowed to introduce a Portex $8.5 \mathrm{~mm}$ endotracheal tube. The head of the manikin was fixed in the sniffing position with screws. For each laryngoscopy, the forces measured by the sensors of the manikin (Fma and Fmt) as well as those determined by the measuring laryngoscope ( $\mathrm{Ft}$ and $\mathrm{Fm}$ ) were recorded. An example of a typical recording is shown in Figure 3.

The participants were not informed of the purpose of this study, nor were any comments made about the way

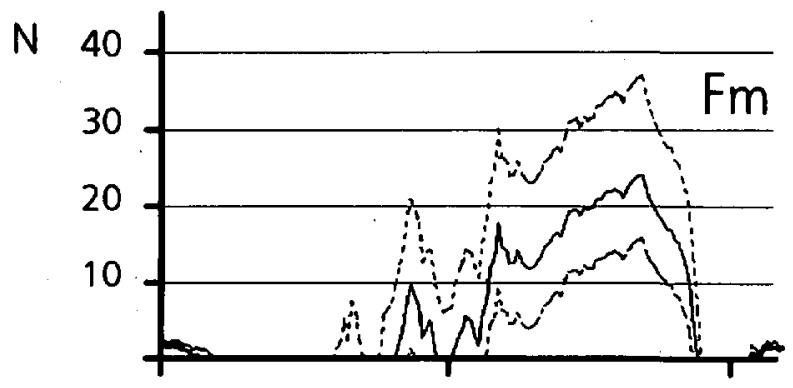
laryngoscopy was performed. During laryngoscopy, only the investigator and the study participant were present.

The best view obtained during laryngoscopy was determined by the investigator by asking the intubator which (and how much of the) structures in the larynxpharynx area of the manikin were identified. Subsequently, this view was graded according to Cormack and Lehane; ${ }^{8}$ grade 1, most of the cords visible; grade 2 , less than half of the cords visible; grade 3 , only the epiglottis visible; and grade 4, not even the epiglottis visible. After each intubation attempt the investigator determined the position of the tube by looking at the transparent trachea at the back of the manikin which was not visible to the intubator. The tip of the tube in the trachea represented successful intubation.

\section{Statistical analysis}

Analysis of variance (ANOVA) was used to test for differences in continuous variables among groups. If this test proved significant, pairwise comparisons of groups were performed with Fisher's least significant difference test. Logarithmic transformation to obtain approximate normal distribution was performed when appropriate. The chi-squared test was used to study the differences between participant groups in the best view obtained. Level of experience was defined assuming staff anaesthetists, residents, nurse anaesthetists, surgeons and students having a decreasing level of experience in this order. The influence of level of experience on the laryngoscopic factors was tested by means of the Spearman rank correlation test or the unpaired Student's $t$ test. Linear regression analysis was used to compare the readings of the measuring laryngoscope with the readings of the sensors in the manikin. A $P$ value $<0.05$ was considered statistically significant.

FIGURE 3 Typical recording of the forces during laryngoscopy. Ft and $\mathrm{Fm}$, forces exerted on the tongue and on the maxillary incisors in the axial direction, measured by the modified laryngoscope. The $95 \%$ confidence intervals of $\mathrm{Ft}$ and $\mathrm{Fm}$ are shown by the dotted lines. Fma and $\mathrm{Fmt}$, forces exerted on the incisors in the axial and transverse direction, measured by the sensors in the manikin. 
TABLE I Laryngoscopic factors determined in the unmodified and modified manikin

\begin{tabular}{lllllll}
\hline \multicolumn{3}{l}{ Unmodified manikin } & \multicolumn{3}{l}{ Modified manikin } \\
\hline$n$ & 20 & & & 30 & & \\
$\mathrm{t}(\mathrm{s})$ & 21.6 & $(11.9)$ & {$[9.6-52.8]$} & 18.8 & $(9.7)$ & {$[6.7-49.0]$} \\
Ftmax (N) & 93.8 & $(18.3)$ & {$[64.2-142.9]$} & 47.8 & $(13.7)$ & {$[32.5-96.7]$} \\
Ftmean (N) & 49.4 & $(7.9)$ & {$[35.1-68.1]$} & 25.2 & $(7.9)$ & {$[17.6-58.0]$} \\
Fmmax (N) & 74.3 & $(31.4)$ & {$[13.7-147.8]$} & 21.6 & $(19.2)$ & {$[3.2-90.7]$} \\
Fmmean (N) & 32.4 & $(18.4)$ & {$[3.7-77.8]$} & 7.3 & $(10.3)$ & {$[0.2-50.0]$} \\
\hline
\end{tabular}

Only results of experienced intubators (i.e., anaesthetists and residents) are shown.

$\mathrm{t} 1$, duration of laryngoscopy; $\mathrm{Ft}$, forces on the tongue; $\mathrm{Fm}$, forces on the maxillary incisors.

Data are mean (SD) and [range].

\section{Results}

The mean (SD) [range] values of the application points of the forces on the tongue and the maxillary incisors as measured from the tip of the blade were in the unmodified manikin $2.8 \mathrm{~cm}(0.8)$ [1.9-5.1] and $9.0 \mathrm{~cm}(1.0)$ [7.6-10.6]. In the modified manikin these values were $2.1 \mathrm{~cm}(0.6)$ [0.9-3.4] and $9.7 \mathrm{~cm} \mathrm{(0.4)} \mathrm{[8.9-10.6],}$ respectively. Table I shows the laryngoscopic factors determined in the unmodified and modified manikin.

The duration of laryngoscopy in residents was shorter and in students longer than in the other groups (ANOVA: $P<0.0001$ ). Duration of laryngoscopy was related to level of experience $(P=0.001, \mathrm{r}=0.37)$. There were no differences among the groups for the forces exerted on the tongue and on the teeth, except for the residents in whom Fmmean, Fmamax, Fmamean and Fmtpmax were lower than in the other groups (ANOVA; $P=0.03, P=0.03, P=0.03$ and $P=0.03$, respectively. Level of experience was related to Fmtpmax $(P=0.04, \mathrm{r}=0.24)$. In addition, Fmtnmax was less in experienced intubators (anaesthetist and residents) than in inexperienced intubators (all other groups) (Student's t test: $P=0.04$ ) (Table II).

Maximal transverse forces oriented toward the base of the skull (Fmtpmax) were between 0 and $10 \mathrm{~N}$ in 46 cases $(61 \%)$, between 10 and $\geq 20 \mathrm{~N}$ in 21 (28\%) and $20 \mathrm{~N}$ (maximum 46.5 ) in $8(11 \%)$. Transverse forces oriented toward the intubator (Fmtnmax) were between 0 and $-10 \mathrm{~N}$ in 69 cases $(92 \%)$, in between 10 and $-20 \times 3(4 \%$ ) (all three were performed by students) and in $-20 \mathrm{~N}$ (maximum $-36.4 \mathrm{~N}$ ) $3(4 \%$ ) (performed by a nurse, a surgeon and a student) (Figure 4).

At full exposure of the glottis, the misreading of the sensors in the manikin was $2.2 \mathrm{~N}$ to small in the axial direction and $1.6 \mathrm{~N}$ too large in the transverse direction. There was a relation between Fmmax and Fmamax $(P<$ $0.0001, r=0.93)$ and between Fmmean and Fmamean $(P<0.000, \mathrm{r}=0.97)$. The average difference between Fmmax and Fmamax was 3.6 $\mathrm{N}(\mathrm{SD}=7.9 \mathrm{~N})$ and between $\mathrm{Fm}$ mean and Fma mean 1.3 N $(\mathrm{SD}=2.1 \mathrm{~N})$.
In 72 participants intubation was successfully carried out. However, one nurse and two surgeons positioned the tube in the oesophagus. The best view obtained during laryngoscopy, which was related to level of experience $(P=0.002, \mathrm{r}=0.35$ ) (Table III).

\section{Discussion}

The results of the present study indicate that transverse forces on the maxillary incisors in $40 \%$ of the laryngoscopies reach values greater than $10 \mathrm{~N}$ and in $15 \%$ greater than $20 \mathrm{~N}$; forces up to even $50 \mathrm{~N}$ were measured. Forces greater than $10 \mathrm{~N}$ were in $39 \%$ of laryngoscopies oriented toward the base of the skull and in only $8 \%$ toward the intubator. Close observation during laryngoscopy revealed that the forces toward the base of the skull were the result of using the teeth as a fulcrum of leverage, whereas the forces toward the intubator were generated during careless withdrawal of the blade out of the mouth. Both actions have been recognised as a mechanism for dental damage.'

This brings us to the question: "What magnitude of transverse force will damage the teeth"? Unfortunately, for obvious ethical reasons, few data are available on this subject. In addition, a simple answer to this question does not exist because the damage these forces will inflict is related to the balance between and the magnitude of these forces and their application point on the teeth, and on the other the mechanical characteristics of the teeth and their fixation to the maxilla.

Apart from easily detectable damage that forces can inflict on teeth, such as luxation and fracture of the crown,,${ }^{9,10}$ transverse forces may also result in less easily detectable damage, resulting from only slight displacement. ${ }^{5}$ This may lead to damage to the neurovascular bundle that enters the tooth at the apical foramen and will result in loss of sensibility of that tooth, which will be permanent when the bundle is ruptured and the dental pulp becomes necrotic. This mechanism of dental damage does not seem to have been recognised in the anaesthetic literature. In contrast, in dental traumatology this 
TABLE II Laryngoscopic factors

\begin{tabular}{|c|c|c|c|c|c|}
\hline & Anaesthetists & Residents & Nurses & Surgeons & Students \\
\hline \multicolumn{6}{|c|}{ Laryngoscope } \\
\hline - Mean & 22.7 & $14.8^{*}$ & 23.0 & 21.7 & $34.6 \dagger$ \\
\hline$-\mathrm{SD}$ & 11.8 & 4.8 & 7.3 & 11.3 & 12.7 \\
\hline - range & $6.7-49.0$ & $7.2-24.4$ & $12.1-41.7$ & $8.5-45.7$ & $17.8-65.9$ \\
\hline \multicolumn{6}{|c|}{$\mathrm{Ftmax}(\mathrm{N})$} \\
\hline - Mean & 50.0 & .45 .6 & 55.4 & 50.1 & 48.2 \\
\hline - SD & 16.2 & 10.7 & 16.7 & 19.9 & 13.7 \\
\hline - range & $34.9-96.7$ & $32.5-71.8$ & $34.2-84.7$ & $28.9-100.7$ & $29.5-80.7$ \\
\hline \multicolumn{6}{|c|}{$F$ tmean $(\mathrm{N})$} \\
\hline - Mean & 25.6 & 24.9 & 27.1 & 24.2 & 22.8 \\
\hline - SD & 10.1 & 5.2 & .6 .5 & 6.5 & 5.7 \\
\hline - range & $17.8-58.0$ & $17.6-37.9$ & $14.8-39.2$ & $17.0-39.1$ & $13.2-35.8$ \\
\hline \multicolumn{6}{|c|}{$F \operatorname{mmax}(\mathrm{N})$} \\
\hline - Mean & 30.6 & $12.5 \ddagger$ & 31.7 & 36.1 & 34.6 \\
\hline - SD & 23.3 & 6.5 & 17.3 & 25.9 & 24.8 \\
\hline - range & $3.2-90.7$ & $3.4-27.4$ & $6.4-62.7$ & $2.2-103.1$ & $1.7-75.2$ \\
\hline \multicolumn{6}{|c|}{ Fmmean $(\mathrm{N})$} \\
\hline - Mean & 11.7 & $3.0^{*}$ & 9.3 & 11.9 & 10.1 \\
\hline - SD & 13.1 & 2.5 & 6.3 & 10.1 & 7.9 \\
\hline - range & $0.5-50.0$ & $0.2-7.9$ & $0.3-22.2$ & $0.3-38.4$ & $0.1-25.9$ \\
\hline \multicolumn{6}{|l|}{ Manikin } \\
\hline \multicolumn{6}{|c|}{ Fmamax $(\mathrm{N})$} \\
\hline - Mean & 29.1 & $11.9 \S$ & 27.4 & 32.6 & 26.5 \\
\hline$-\mathrm{SD}$ & 21.5 & 8.9 & 13.8 & 25.3 & 20.0 \\
\hline - range & $2.7-87.2$ & $0.6-30.5$ & $4.5-52.8$ & $3.3-82.5$ & $0.8-61.2$ \\
\hline \multicolumn{6}{|c|}{ Fmamean $(\mathrm{N})$} \\
\hline - Mean & 11.0 & $2.6 \S$ & 8.3 & 10.0 & 7.7 \\
\hline - SD & 12.6 & 3.5 & 6.0 & 9.2 & 6.5 \\
\hline - range & $-0.1-47.5$ & $-1.3-10.8$ & $0.2-20.0$ & $0.5-29.6$ & $-1.5-19.7$ \\
\hline \multicolumn{6}{|c|}{ Fmtpmax $(\mathrm{N})$} \\
\hline - Mean & 9.5 & $4.2^{*}$ & 9.9 & 12.7 & 12.6 \\
\hline - SD & 6.9 & 1.9 & 6.0 & 11.2 & 9.1 \\
\hline - range & $2.1-26.5$ & $1.6-7.3$ & $1.0-21.1$ & $3.1-46.5$ & $1.3-29.6$ \\
\hline \multicolumn{6}{|c|}{ Fmtpmean (N) } \\
\hline - Mean & 3.1 & 1.2 & 2.7 & 3.6 & 3.5 \\
\hline - SD & 3.1 & 0.7 & 2.1 & 4.0 & 2.6 \\
\hline - range & $0.3-11.7$ & $0.4-2.3$ & $0.4-7.6$ & $0.4-16.3$ & $0.3-9.5$ \\
\hline
\end{tabular}

The values of Fmtn are described in the text and partly shown in Figure 3.

$\mathrm{tl}$, duration of laryngoscopy; $\mathrm{Ft}$, forces on the tongue; $\mathrm{Fm}$, forces on the maxillary incisors; max, maximum value; mean, mean value.

*The values of the duration/forces are shorter/less compared to all other groups.

†This value is longer than in all other groups.

¥This value is borderline less compared to all other groups $(P=0.06)$.

$\S$ The values are less compared to all other groups except for the student group.

mechanism is well known ${ }^{5}$ and it is reported that in $17 \%$ of traumatic injuries with no directly visible damage of the tooth the dental pulp will become necrotic. ${ }^{11}$ In many patients, denervation of a tooth may not be immediately recognised and it is unlikely that when finally confirmed, its origin will be traced back to the laryngoscopy. Although the amount of force needed to inflict this type of damage is unknown, it will certainly be less than the amount of force needed to produce the easily detectable damage. It seems, however, reasonable to state that transverse forces greater than $10-20 \mathrm{~N}$, especially in patients with periodontal disease and restored teeth, may result in dental morbidity and that the lowest forces possible should be applied to these teeth.

Another important aspect of this study is the observed effect of experience on laryngoscope handling. In accordance with previous studies, ${ }^{4,12}$ level of experience proved to be related to the duration of laryngoscopy' and 


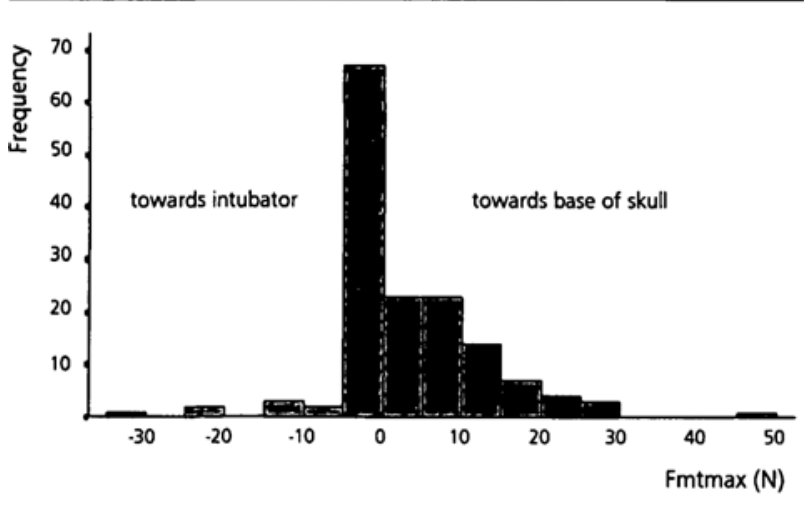

FIGURE 4 Histogram showing the distribution of the forces on the maxillary incisors in the transverse direction (Fmt). For each recording, the maximal force in the positive (towards the base of the skull) (Fmtpmax) and the negative direction (towards the intubator) (Fmtnmax) is shown.

TABLE III Best view obtained during laryngoscopy

\begin{tabular}{llll}
\hline & \multicolumn{3}{l}{ Best view obtained ${ }^{*}$} \\
\cline { 2 - 4 } & 1 & 2 & 3 \\
\hline Anaesthetists & 13 & 2 & - \\
Residents & 14 & 1 & - \\
Nurses & 13 & 1 & 1 \\
Surgeons & 10 & 5 & - \\
Students & 7 & 7 & 1 \\
\hline
\end{tabular}

*Best view was assessed according to the grading system of Cormack and Lehane [8]; 1, most of the cords visible; 2 , less than half of the cords visible; 3 , only the epiglottis visible; 4 , not even the epiglottis visible. Values are number of participants per group.

the best view obtained and not to the axial forces exerted on the teeth. In addition, this study demonstrated that experience is related to the transverse forces directed towards the base of the skull as well as towards the intubator.

Another striking observation related to experience, is the performance of the residents. They were faster than all other participants and exerted less force on the teeth in both the axial and transverse direction than most other groups including the anaesthetists. This observation suggests that the number of laryngoscopies performed recently might be more important than the total number performed throughout a career.

One of the drawbacks of this study was that the readings of the sensors in the manikin have limited accuracy. The maximal misreading in the axial direction was $2.2 \mathrm{~N}$ too small and in the transverse direction this was $1.6 \mathrm{~N}$ too large. However, these misreadings were determined by the investigators at full exposure of the glottis without exerting any force on the maxillary incisors, which takes greater forces on the tongue than those exerted by the participants of the study. As the misreadings of the sensors in the manikin are related to the forces exerted on the tongue, the inaccuracies of the values obtained in this study are smaller, and not considered to be a problem.

Another drawback of this study was that one can question whether a manikin study can adequately represent the clinical situation. ${ }^{13}$ In addition, one might argue that the effects of experience are most prominent in the difficult intubation. However, to perform these kind of studies in patients would lead to ethical problems.

The last issue to be addressed by this study is the relation between the forces on the teeth (Fm) as determined by the measuring laryngoscope and the forces on the teeth in the axial direction (Fma) as measured by the sensors in the manikin (Table II). There proved to be a highly significant relationship between the values produced by both sensors, the overall mean differences between the maximal and mean values of these forces were $3.6 \mathrm{~N}$ and $1.3 \mathrm{~N}$, respectively and the graphical representations of both recordings looked very much alike. These data support the validity of the measuring laryngoscope as a method to measure axial forces on maxillary incisors in groups of patients and, therefore, strongly supports the conclusions of previous reports. ${ }^{3,4}$

In conclusion, in this study the presence of transverse forces applied during laryngoscopy is demonstrated. In $15-40 \%$ of laryngoscopies these forces reached values which might lead to dental damage, especially in patients with poor dentition. In contrast to the effect on forces exerted in the axial direction, experience proved to have a beneficial effect on the forces in the transverse direction.

\section{Acknowledgements}

We are grateful to all participants for their kind co-operation in this study. We thank Ruud Niesing (M Eng), Henk van de Giessen (E Eng) and Gerard Maas, Central Instrumentation Department, Erasmus University Rotterdam, for their expert technical support. We thank Laerdal Benelux NV for generously providing the Laerdal Airway Management Trainer and Laraine Visser-Isles for her expert editorial assistance.

\section{References}

1 Otto $C W$. Tracheal Intubation. In: Nunn JF, Utting JE, Brown BR Jr (Ed.). General Anaesthesia, 5th ed. London: Butterworths, 1989: 512-39.

2 Roberts $I T$. Fundamentals of Tracheal Intubation. Boston, Massachusetts: Grune \& Stratton, 1983: 75-80.

3 Bucx MJL, Snijders CJ, van Geel RTM, et al. Forces acting on maxillary incisor teeth during laryngoscopy using 
the Macintosh laryngoscope. Anaesthesia 1994; 49: 1064-70.

4 Bucx MJL, van Geel RTM, Wegener JT, Robers C, Stijnen $T$. Does experience influence the forces exerted on maxillary incisors during laryngoscopy? A manikin study using the Macintosh laryngoscope. Can J Anaesth 1995; 42: 144-9.

5 Andreasen JO, Andreasen FM. Textbook and Color Atlas of Traumatic Injuries to the Teeth, 3rd ed. Copenhagen: Munksgaard, 1994: 162-4.

6 Bucx MJL, Scheck PAE, van Geel RTM, den Ouden AH, Niesing $R$. Measurement of forces during laryngoscopy. Anaesthesia 1992; 47: 348-51.

7 Pronk CNA, Niesing R. Measuring hand-grip force, using a new application of strain gauges. Med Biol Eng Comput, 1981; 19: 127-8.

8 Cormack RS, Lehane J. Difficult tracheal intubation in obstetrics. Anaesthesia 1984; 39: 1105-11.

9 Burton $J F, B a k e r A B$. Dental damage during anaesthesia and surgery. Anaesth Intensive Care 1987; 15: 262-8.

10 Clokie C, Metcalf I, Holland A. Dental trauma in anaesthesia. Can J Anaesth 1989; 36: 675-80.

11 Andreasen $F M, Y u Z$, Thomsen $B L$, Andersen $P K$. Occurrence of pulp canal obliteration after luxation injuries in the permanent dentition. Endodontics and Dental Traumatology 1987; 3: 103-15.

12 Bishop MJ, Harrington RM, Tencer AF. Force applied during tracheal intubation. Anesth Analg 1992; 74: 411-4.

13 Chopra V, Gesink BJ, de Jong F, Bovill JG, Spierdijk J, $B$ rand $R$. Does training on an anaesthesia simulator lead to improvement in performance? Br J Anaesth 1994; 73: 293-7. 